\title{
PUTTING “PLACE” IN A MULTISCALE CONTEXT: PERSPECTIVES FROM THE SUSTAINABILITY SCIENCES
}

\author{
Thomas J. Wilbanks \\ Oak Ridge National Laboratory \\ USA
}

Since the inception of "sustainability science," a central precept has been that causal relationships are too complex to trace out at large scales. For this reason, it is argued that processes which drive change at a global scale can only be unraveled by careful place-specific research. Moreover, many of the most important topics of recent sustainability research interest, such as "resilience" and "adaptation," involve so many driving forces that are geographically and socioeconomically diverse that what makes sense for one place seldom makes sense for many others.

At the same time, it is increasingly clear that the dynamics and sustainability of places defined at any geographical scale are in fact shaped by and a shaper of realities at other scales. "Place" sits within what the Millennium Ecosystem Assessment called a "loosely nested multiscale" context (2003; also Capistrano et al., 2003, and Reid, 2006), in which such diverse processes as information flow, access to resources, and control of key decisions cross geographic scales continually (Gibson, Ostrom, and Ahn, 2000). How, then, do we frame discussions of place in a multi-scale context?

This paper summarizes a number of perspectives that have emerged from the sustainability sciences in recent decades (NRC, 1999; Kates et al., 2001; NRC, 2006; Kates, 2010) that shed light on the role of place in multi-scale sustainability science and vice-versa, ranging from the importance of the "co-production" of knowledge for sustainable development to threats to a "sense of place" from global environmental and economic changes.

Clearly, scholarly attention to place in a multiscale concept is shared by a number of research communities, especially a rich tradition of research on place as politically contested space (e.g., Massey, 1995; Verstraete and Cressell, 2002); Naughton, 2014). Agnew offers a notable review of differences between the philosophical foundations of a focus on space vs. place (Agnew, 2011), which in practice have led to distinct contrasts between a focus on "how large" and a focus on "how fair." Based on his review of the histories of the terms, for this paper space is defined as a system of locational interactions, while place is defined as a locational setting for mediating physical, social, and economic processes. 
Sustainability science traditions have been focused on challenges in integrating knowledge about nature and society as a research objective, where "scale" is used as one of a number of structural organizing concepts and "place" is not usually an organizing concept, although it is incorporated in research at several scales. Its importance is often heightened by the fact that, as sustainability science tries to unravel natural system - human system interactions at scales from microbial to global, its empirical finding has been that a small regional scale is the one where such integrative analysis is often most fruitful (e.g., Corell, 2000; Kates, 2010), in contrast to macroscale approaches widely used by other nature-society research communities.

These traditions intersect with the political-economy oriented place traditions, where place is seen as a frequent focus of struggles over power, control, and equity, with scale only one of many factors shaping how places work. These intersections, some of them noted below, offer potentials for research that might interest both communities and benefit a number of space/place research discourses.

\section{$\underline{\text { Scale and sustainability revisited }}$}

Place matters. We know intuitively that sustainability in a neighborhood is different from sustainability as a nation (Holling, 1995). For most people, the sustainability of their own neighborhood matters more to them than sustainability in distant neighborhoods. And we sense that what happens with sustainability at one scale affects sustainability at other scales; examples range from air pollution to migration, technological change, and conflict.

Developing theoretical structures to represent these truisms has proved to be difficult, not because we do not understand place but because sustainability is such an elusive goal. For instance, sustainability for what? For whom? How is it measured? How does it relate to multiple causation and complex feedbacks? How is it dependent on social contexts: the sustainability of social processes that shape driving forces and responses which determine the sustainability of systems that we care about? How is place at least a part of the answer to these kinds of questions?

Even given some unavoidable ambiguity about operational definitions of sustainability, we know that place matters for sustainability because geographic scale matters. It affects how the world works, how we perceive and learn about the world, and the things we do to make the world better (Wilbanks and Kates, 1999; Wilbanks, 2014).

Scale affects how the world works because natural and human systems have characteristic geographic domains (spheres of activity), related to how those systems organize and operate. Within those domains, activities tend to cluster at identifiable sub-domains, often nested in hierarchies. The domain of one system is often different from the domains of other systems with which it interacts (Clark, 1985; Wilbanks and Kates, 1999; Wilbanks, 2003; Wilbanks, 2006). Moreover, 
ecologists have argued for a century that morphologies affect system dynamics and sustainability. For example, larger organisms are characteristically more complex but less agile, while smaller organisms are proportionally simpler but stronger (e.g., Thompson, 1992; Bonner, 2007).

Some of the implications of differences in the scale of domains are quite familiar. For instance, the importance of cross-border linkages in system dynamics increases as the scale shrinks (e.g., the "multiplier" in regional economics); and likelihoods of exposures to low-probability, high-consequence events are lower for small areas than large, while consequences of such events are higher for small areas than large areas.

Scale affects how we learn about the world because our lenses for observing and analyzing are partly defined by the scale of attention (e.g., Cheng and Daniels, 2014). As indicated above, one of the most powerful findings from the emerging field of sustainability science during the 1990s was that a place-based context is often essential for integrative sustainability research, because integrating complex interactions among a host of variables with some bearing on sustainability is more tractable at the scale of a relatively small region than at larger scales (Corell, 2000: Kates et al., 2001; Turner et al., 2003). Moreover, the amount of variance between smaller-scale geographic units that we see in observing sustainability processes and phenomena (i.e., the "signal to noise ratio") changes with the scale of observation (e.g., Figure 1; also see Costanza and Maxwell, 1994). In fact, in relatively large, diverse nations, a persistent cross-scale policy issue is whether national policy guidelines should recognize regional and local differences rather than defining "one size fits all" standards, e.g., for a minimum wage when the local cost of living may vary significantly (Wilbanks, 1985).

This relatively local orientation differs from many other fields of place-related research, where comparative analysis at a macroscale is more common, especially in fields where quantitative data on spatial units at national and smaller scales are readily available such as economics, demography, and health. Characterizations of this approach include Antal, Kierkes, and Weller, 1987. Although macroscale comparative research has been less prominent in nature-society studies, there are examples of valuable applications such as Rosa, et al., 2010, and Rudel, 2009.

In much more basic terms, however, the questions we ask about sustainability tend to differ according to the geographic scale of our interest and experience, and the data available for analysis are often different depending on the scale of analysis (Wilbanks and Kates, 1999; Rosswell, Woodmansee, and Risser, 1998; Turner, O'Neill, and Gardner, 1989). And perceptions of reality and meaning can be determined by relationships between scale and familiarity. For instance, technology transfer during the Green Revolution in India during the late 1960s was slowed by the fact that local farmers were unwilling to believe that demonstrations of improved technologies and practices only tens of miles away were relevant to their unique local circumstances (Wilbanks, 1972, and 1980). In the early 1980s, it was 
clear that attitudes toward the operation of nuclear facilities were sharply different according to the size of the facilities (in essence, the perceived spatial scale of any potential threat), as university students and faculty protested nuclear power plant construction while small nuclear reactors were operating on some of their campuses in connection with research and learning about nuclear science and engineering (Wilbanks, 1984; also see Wilbanks et al., 2009).

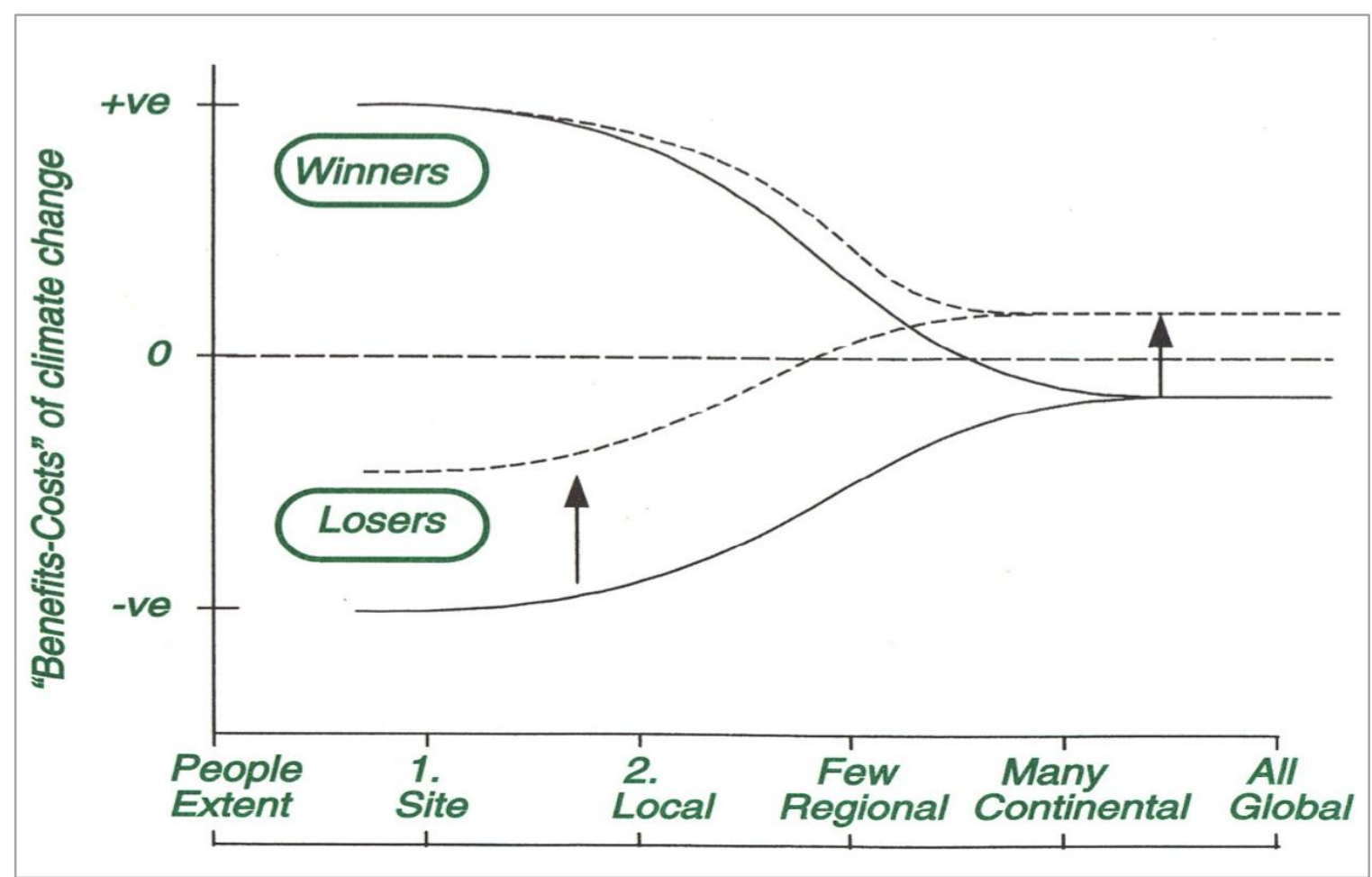

Figure 1. Effects of geographic/economic scale on net gain (benefits minus costs) arising from effects of climate change on society and the role adaptation might play in mitigating the more negative outcomes (adapted from Environment Canada, 1997: 298: Wilbanks, 2003). The vertical axis indicates variance in net gains.

In addition, the things we do to make the world better are often embedded in issues related to scale. Most sustainability actions are taken by actors whose responsibilities and administrative structures are related to geographic boundaries. These boundary systems are not necessarily consistent with the geographic scales of natural and social systems: they may be too large, too small, very poorly aligned (familiar examples include river basins, coastlines, and biomes relative to political boundary systems). Key issues include (a) at which scale is a sustainability action most effective and (b) how complementary roles of different scales can be combined.

One example of a scale-related factor is a goal of truly broad-based stakeholder participation. Decades of geographic research indicate that consensual decisionmaking depends heavily on personal relationships and communications (e.g., Parkes and Thrift, 1980, after Hagerstrand, 1975; Wilbanks, 1975). Direct personal communications are subject to distance decay, which means that the scale at which 
such a consensus can be reached is limited for some purposes. As a historical case in point, consider participative decision-making through commune-scale governmental units in President Tito's Yugoslavia in the 1960s and 1970s. A great many of the powers of government were transferred to these units, which adjusted their size if they were too large for consensual action or too small for effective action. By 1977, they had evolved to the size distribution shown in Figure 2, generally quite small.

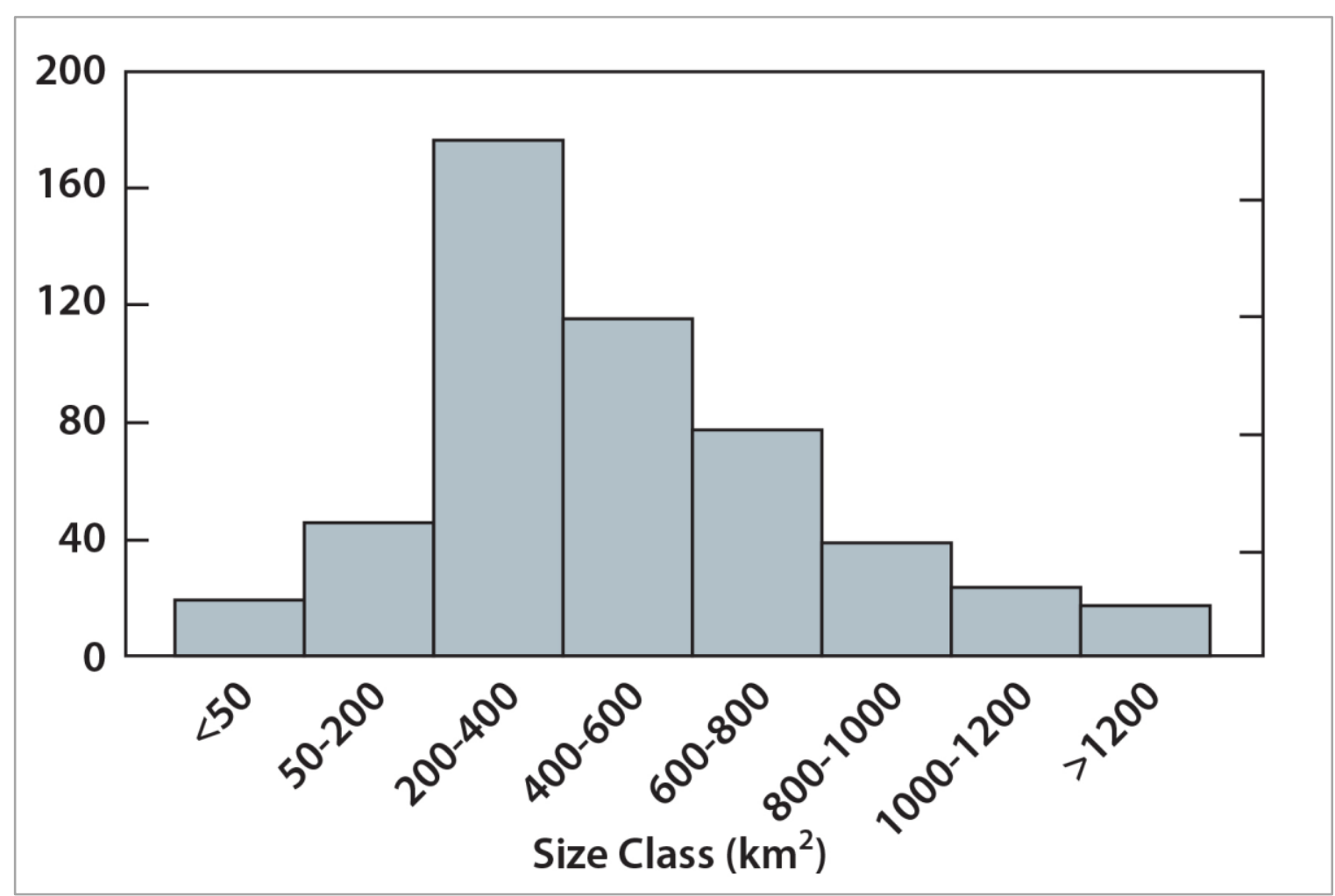

Figure 2. Size distribution of Yugoslav Communes, 1977 (Wilbanks, 1994), reflecting a rare realworld experiment with determining the geographic scale at which consensual sociopolitical decisionmaking works best.

\section{Embedding scale discussions in a multi-scale perspective}

One consistent finding has been that different sustainability actions call for different scales of attention. For example, actions to reduce the rate of greenhouse gas emissions are associated with different scale domains than adaptive actions to address climate change impacts (Wilbanks and Kates, 1999; ACC, 2011).

Clearly, certain sustainability roles can only be played at a local level, where local knowledge can be accessed and certain social communication networks can be used. But local action is often limited if left to its own devices: e.g., limits on local financial and technology resources (Wilbanks, 2007). Moreover, actions often combine 
elements defined at different scales; for instance, greenhouse gas emissions are associated with localized sources and stakeholders, but the ownership and management of sources often reside at much larger scales (AAG, 2003). Figure 3 is one illustration of such differences in roles.

In sustainability research in general, we find that we often understand differences between geographic scales better than interactions between geographic scales, in part because data on linkages between people, institutions, and resource flows between scales is often limited - especially those related to how decisions are made. This is less true when linkages involve measurable commodities (see, for example, Graedel and van der Voet, 2010). In many cases, however, such linkages and interactions are more important for sustainability than aggregate scale differences, and different trajectories of interaction can make a difference for outcomes - which calls for making relatively detailed research attention a high priority. In fact, it can be argued that no place is sustainable if other places with which it is related are not sustainable, because the resulting effects can spread spatially, such as conflict and disease (Wilbanks, 1994; also see "locality" as a construct within global networks (Rutgers University, 2000).

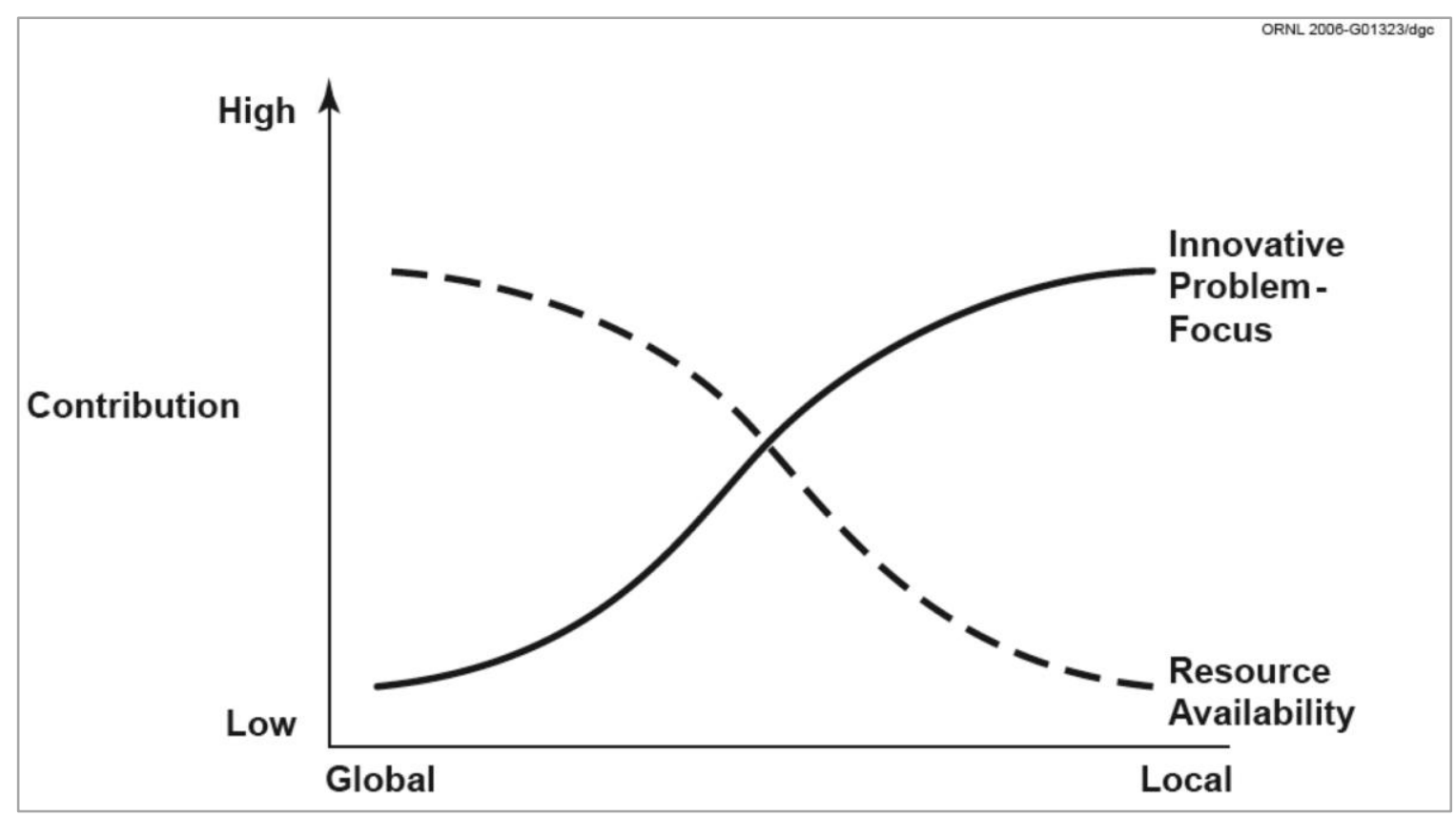

Figure 3. Different actions call for different scales of attention (Wilbanks, 2007). For example, larger scales tend to have greater access to financial and scientific resources, while smaller scales tend to have a greater capacity for innovative problem-solving related to local contexts.

Cross-scale interactions can differ in their strength (powerful vs. weak), their constancy (constant vs. intermittent), their directionality (one way vs. another - or mutual), their resolution (focused vs. broad), their context (additive or contradictory relative to other processes), their effect (stabilizing or destabilizing 
controlling or enabling), and/or their intent (explicit, implicit, or unintended)(Wilbanks, 2006). For example, looking from the bottom up local processes, phenomena, and actions may affect global processes, phenomena, and actions in either or both of two ways: systemic change, by modifying how global processes function; or cumulative change, through accumulations of localized changes (Turner et al., 1990). Looking from the top down, development literatures indicate that sustainability depends on combining the best of large-scale learning and resources with the best of local-scale knowledge and innovativeness - enabling the co-production of actionable knowledge (Wilbanks and Wilbanks, 2010). Figure 4 illustrates the kinds of cross-scale interactions that can matter in global change.

Analytically, the goal is often to understand both scale differences and scale relationships in order to arrive a multiscale understandings. Most commonly, this is done by converging on a single "meso" or regional scale, involving either upscaling or downscaling or both. The alternative is to seek a multi-scale or meta-scale synthesis, related to such methodological conceptions as "strategic cyclical scaling" and "hierarchical patch dynamics" (Wilbanks, 2003). Figure 5 illustrates a notional approach to scale integration.

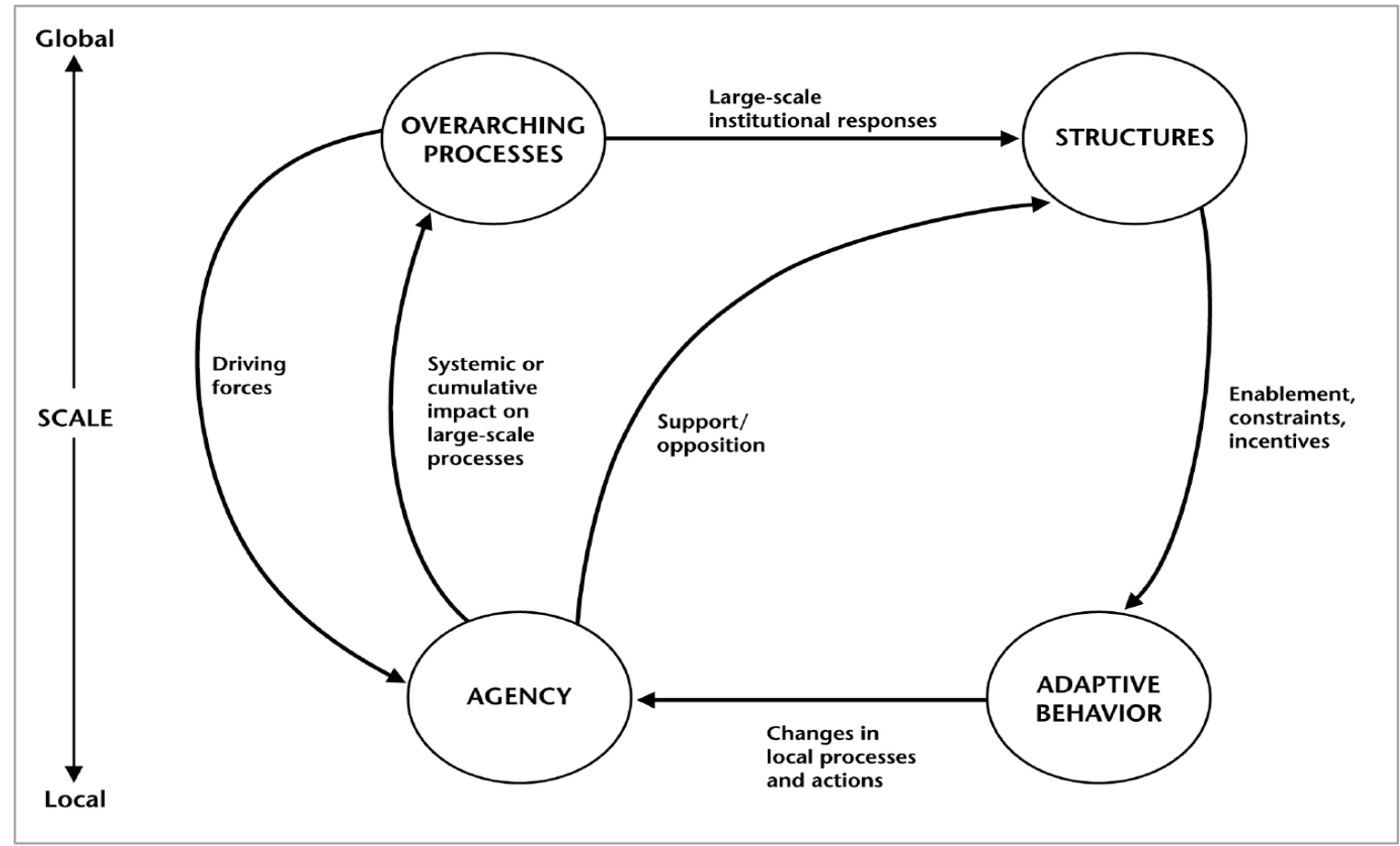

Figure 4. Macroscale/microscale interactions in global change (AAG, 2003; Wilbanks, 2007). Shaped by larger-scale driving forces, local agency results in changes that affect larger-scale processes, sometimes adversely. If those changes call for responses, larger-scale actions feed back to provide incentives for changes in local processes and actions, and the cycle continues. 


\section{Emerging issues for scale and sustainability in an interconnected world}

Putting place into a multiscale context is far from purely a conceptual challenge for any research community. It is emerging as a very practical need in addressing a number of salient issues for nature-society policy and action. Examples include "resilience," adaptation and mitigation responses to concerns about climate change, and technological change as a requirement for the sustainability of nature-society balances in many contexts.

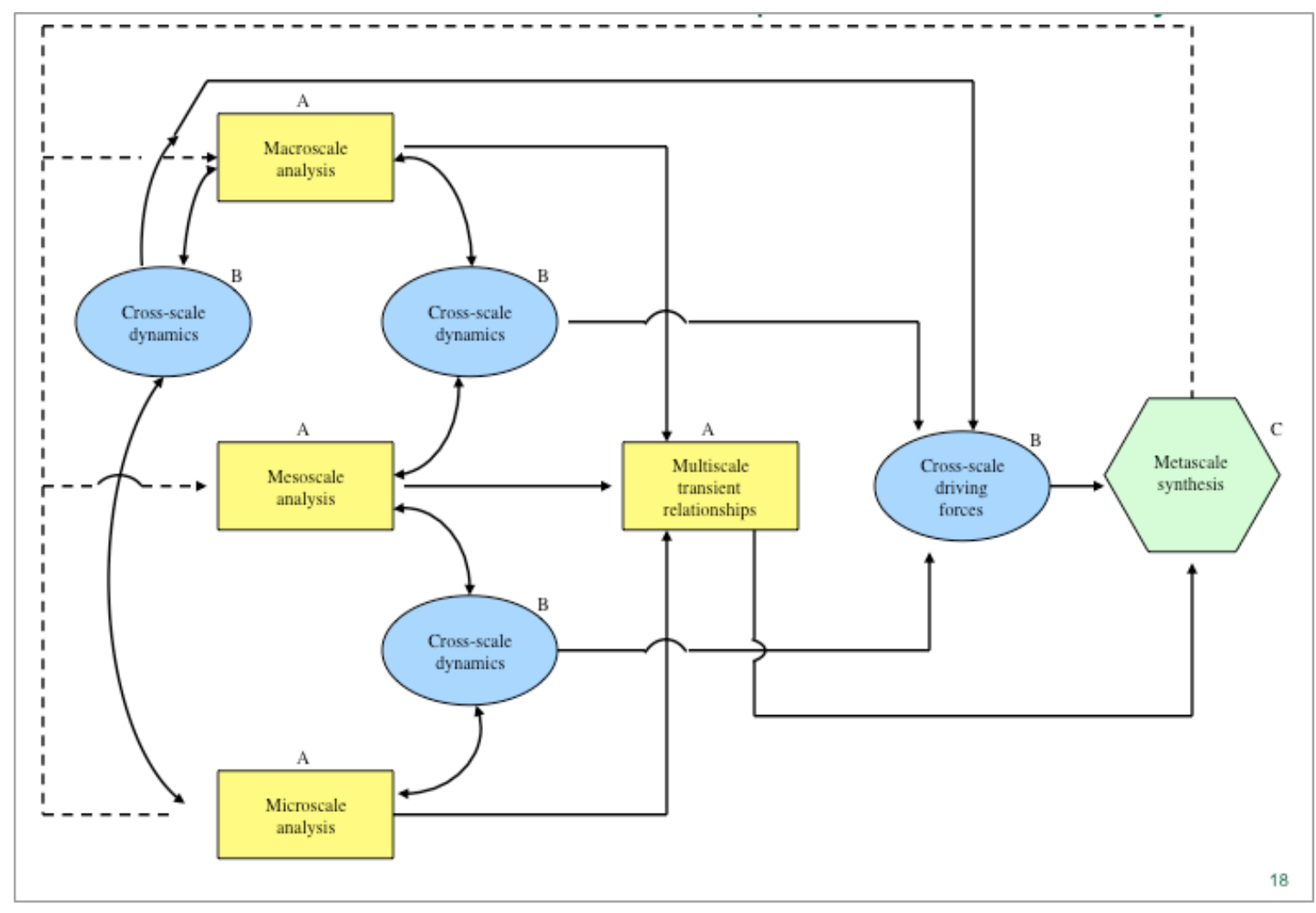

Figure 5. In the long run, we need to be able to integrate both scale differences and scale relationships in multiscale analysis (Wilbanks, 2003). Analyses at different scales provide somewhat different insights, along with analyses of relationships between scales, calling for crossscale integration.

\section{Resilience}

Resilience has grown rapidly as a concept and term that communicates a proactive goal for reducing sustainability stresses, in contrast to "vulnerability," which sounds more passive (CARRI, 2010; Cutter et al, 2008). Like adaptation, resilience overlaps sustainability as a societal goal, as a medium-term strategy that enables the longerterm sustainability of systems that we value (Turner et al., 2003). In the United States, efforts to enhance resilience have tended to focus on two goals: community resilience, or the resilience of cities, towns, and relatively small regions to multiple threats (Wilbanks and Kates, 2010); and the resilience of built infrastructures - such 
as energy, water, transportation, waste management, and communication infrastructures - to impacts of extreme events and climate change (Wilbanks, Fernandez, et al., 2014).

In both of these cases, large-scale science and policy agendas are involved, but strategies and capacity-building are strongly place-oriented in a multiscale context. For instance, community leaders say that community resilience is rooted in a community social dynamic that enables the community to cross institutional boundaries in order to reduce vulnerabilities and/or respond to threats (CARRI, 2011), although some aspects of insurance against and responses to disruptive events are nested in larger-scale institutions. Infrastructure strategies depend heavily on differences between cities and regions in the age and/or excess demands that reduce the ability of infrastructures to cope with any serious source of stress, and they depend heavily on local innovativeness in overcoming obstacles to financing infrastructure replacement or revitalization (Wilbanks, Fernandez, et al, 2014); but they are related to external resources for infrastructure improvement, to technology and other options for improvement, and to linkages between local infrastructures and regional and larger-scale infrastructures.

\section{Climate change responses}

Climate change is a process which combines a host of localized greenhouse gas emissions and a host of place-specific impacts with the global scale of atmospheric dynamics and economic and political forces. Although the most salient activities tend to occur at international and national scales, in fact both potentials for and evidence of bottom-up actions in local places offer more encouragement. Most of the science and policy attention to date has been oriented toward how place matters for adaptive risk management, but leadership roles of bottom-up institutions in emission reduction are also emerging.

\section{○itigation}

A pioneering effort to understand how local actions matter for climate change mitigation was AAG, 2003, which studied potentials for local roles in emission reduction in four relatively small parts of the United States. The study concluded that what local agency needs in order to initiate significant actions for greenhouse gas emission reduction are several conditions: 1) growing evidence of impacts on that locality of climate change; 2) policy interventions that directly or indirectly associate emission reductions with incentives and assistance for local innovation; and 3) technology alternatives appropriate to local conditions (AAG, 2003). Meanwhile, local agency is a key to effective implementation of policies adopted at larger scales (Figures 3 and 4).

Over the past decade and more, any observer assessing progress with climate policy in the United States would be deeply disappointed at the national scale, but there are a number of encouraging examples of actions at a regional and state scales. 
Examples include the enactment by states (often led by California) of vehicle emission standards and other emission caps and standards, as well as renewable energy portfolio standards for electric utilities (NAS/NRC, 2010b). At the regional scale, a Regional Greenhouse Gas Initiative seeks to reduce emissions in nine states in the Northeast (Burtrow and Wortman, 2012; WRI, 2012). Cities and metropolitan areas have also supported mitigation initiatives through ICLEI (Local Governments for Sustainability) and the U.S. Conference of Mayor's Climate Protection Agreement. These bottom-up initiatives are a source of support for larger-scale policies and a source of learning about innovative approaches. Other observers, however, cite cases where local actions have hindered higher-level actions (Rabe, 2004, 2009).

\section{○ Adaptation}

The same general observation would be true for climate change adaptation, where policies at a national scale in the US have been limited largely to directives to federal agencies; but a principal reason is that what adaptations make sense are often very localized. Adaptations vary with the threat, the scale, characteristics of local contexts that shape vulnerability, affected populations, and such differences between places as leadership and social dynamics (NAS/NRC, 2010a), rooted in frequent differences in values and priorities (Fresque-Baxter and D. Armitage, 2012). This diversity of contexts makes it difficult to implement adaptation policies top-down; instead, the challenge is to encourage and support the co-development of adaptive risk management responses, arising from participative processes in places.

Some US states have been innovative in adaptation planning (Moser, 2009; NAS/NRC, 2010a; U.S. National Climate Assessment, 2014). More often, however, actual adaptation actions have taken place at a local level, supported by ICLEI and others. A pioneering effort was in King County, Washington, which produced a guidebook for local government adaptation planning (Snover, 2007). The most comprehensive adaptation planning accomplishment has been New York City's PlaNYC, a sustainability and growth management initiative for New York City which included a Climate Change Adaptation Task Force that engaged a variety of private and public sector stakeholders (New York City Panel on Climate Change, 2010). At a much smaller scale, Keene, New Hampshire, has been a notable example of a case study of action in a relatively small community, bridging both adaptation and mitigation (NAS/NRC, 2010a), and Alaska has been a crucible for adaptive responses to impacts that are being observed rather than merely projected.

But, as with mitigation, local and regional adaptation prospects depend considerably on evidence of threats and the availability of technology and policy alternatives developed at national and international scales, along with assistance from expert communities and institutions that work with partners in many places. Meanwhile, local initiatives and experiences become invaluable test-beds for strategies that can be adopted for many other places. 


\section{Technological change}

A fundamental requirement for sustainable development is technological change in order to cope with development stresses and to support innovative problem-solving. Elements of this process include technology invention, the diffusion of known technologies that have advantages over technologies in use, and technology adoption and use. All of these elements have connections with place. For instance, literatures on determinants of invention identify intellectual climates that occur in specific times and places as a key factor in bringing together creative people with different backgrounds to stimulate unexpected and novel insights (Wilbanks, 2011; Merton, 1973; Merton and Barber, 2004; Zucker and Darby, 1996; Hall, 1998).

Because technology innovation, invention, and production tend to be concentrated in particular parts of the world, technology diffusion is inherently multiscale in character (e.g., Parkes and Thrift, 1980). Recent literatures focused on challenges in realizing potentials for technology applications in developing countries have identified problems with the suitability of technologies from the industrialized world -- developed with different conditions in mind - for addressing relatively localized needs and users, along with the value of local knowledge in developing or adapting technology ideas (Wilbanks and Wilbanks, 2010; Cash et al., 2003; e.g., Kristjanson et al., 2009). In other words, the challenge is to entrain talent at all scales through transfers of knowledge that combine both knowledge that exists external to a place with often place-based local knowledge, to enable user-driven coproduction of locally useful technology and institutional improvements. The emerging information technology revolution is becoming a powerful enabler of local access to global and national knowledge, not only about available technologies but also about science and technology challenges, if intellectual property obstacles can be overcome

\section{$\underline{\text { Some consequences for action }}$}

Clearly, multiscale relationships are of great current interest in a host of naturesociety connections, and they are of profound importance in realizing potentials for sustainability. But how do they shape actions, especially actions that depend on integrating forces that operate at different scales (Brasseurs and Rosenbaum, 2009; Adger et al., 2003; Liverman, 2004; Bulkeley and Betsill, 2005)?

What might be done to realize potentials for integrating actions at different scales, to make them far more complementary and reinforcing? In many cases, the experience to date with such initiatives as the US Initiative on Joint Implementation (IJI) and the international Clean Development Mechanism (CDM) suggests that initiatives undertaken at relatively large scales - at least in government - often discourage local agency by bogging down relatively localized (sectoral as well as geographic) action in bureaucratic requirements as a condition for access to financial and other resources (Wilbanks, 2009). Top-down sustainability initiatives are often preoccupied with input accountability, such as criteria for partner 
selection and justifications (often based on relatively detailed quantitative analyses of such attributes as "additionality"), rather than on outcome metrics such as whether the results make a demonstrable contribution to sustainability (regarding metrics, see NAS, 2005).

More generally, it appears that key factors include a kind of mutual trust that is, unfortunately, rare between different scales of at least governmental decisionmaking; roles of intermediary third parties, facilitating cross-scale interactions through personal relationships and associated structures (e.g., Cash and Moser, 2000); and infrastructures for identifying and disseminating information about success experiences, so that individual cases generate benefits beyond their own narrow boundaries (Wilbanks, 2009).

In particular, in cross-scale government interactions, actions at larger scales can discourage local initiatives by embedding the implementation of agendas in standardized bureaucratic structures that complicate access to resources. At the same time, actions at local scales can undermine larger-scale initiatives through political opposition or downright obstruction, by passive resistance such as a denial of useful information, and/or by local redirections (Figure 4). A familiar, often daunting challenge is to find ways to combine the strengths of both scales rather than having them work against each other.

Consider, for example, certain strengths offered by both internal and external assets for relatively local-scale climate change adaptation initiatives. Internally from a local perspective, factors of importance include wealth (or the lack of it), a capacity for collective social action (or the lack of it), economic diversification (or the lack of it), and local leadership (or the lack of it). Externally, factors of importance include linkages that expand the range of alternatives for the locality: financial and human resources, commodities, information; structures that enable adaptive responses such as market and non-market incentives and mechanisms for coordination; risk-sharing approaches such as insurance; and portfolios of locally-appropriate technologies (Wilbanks, 2009).

\section{Possible forces for change in the meaning of place}

The meaning of place for sustainability is constantly changing in response to shifts in the context of our localized experiences. A familiar example is the role of changes in movement technologies that have been reshaping the character of our places for centuries, especially the emergence of automobiles and other highway vehicles (Wilbanks, 1988; Amin et al., 2004). Looking to the future, it appears that largely aspatial information and communication technologies will further change the meaning of place, affecting the value of physical proximity, of personal contact and communication, and of social interactions and groupings (Wilbanks, 2003). Recent studies have suggested the importance for sustainability of "telecoupling:" socioeconomic and environmental interactions over distances that are facilitated by advances in movement technologies (Liu et al, 2013 and 2015; also see Adger, Eakin, and Winkels, 2009. Increased attention to such linkages can contribute to systems 
integration of components of human and natural systems in understanding sustainability, which continues to be a challenge (Liu et al. 2015).

At the same time, global forces and trends are changing the day-to-day lives of many people in localized places, affecting their choices of where to live and affecting the "sense of place" that is a part of how they think about where they are. Sense of place is widely recognized as a factor related to community sustainability (e.g., Stedman, 1999) and to migration as a response to place-focused stresses (Mendoza and Moren-Alegret, 2013), and its underrepresentation of identity and meaning in discussions of climate change response strategies has been argued compellingly (Adger et al., 2011). A number of recent studies have documented the importance of attachment to place in considering responses to climate change threats to particularly vulnerable places, such as communities located in threatened seacoast areas (Agyeman et al., 2009; Chapin et al., 2012; Devine-Wright, 2013; also see Tomaney, 2014, regarding the significance of "belonging").

One vivid example is the way that modern information and communication technologies have made it possible for people with valued and mobile skills to make a living in rather remote locations (Robb and Riebsame, 1997). A second example is economic globalization, which is internationalizing both markets and supply chains for place-based products and services and also ownership structures for local economic activities. In both cases, evidence is emerging that flows between locations are changing the meaning of place in many parts of the world (Amin et al., 2004).

A third example is climate change, which in the coming century will be changing ways of life and place-based landscapes in many parts of the world as their local climates change significantly. For instance, one study projects that with relatively severe climate change, by the end of the century the climate of upstate New York will resemble the current climate of western South Carolina, and the climate of eastern Pennsylvania will resemble the current climate of South Georgia (UCS, 2008). If so, the current sense of place is unlikely to resemble the sense of place in these impacted regions several generations from now.

\section{$\underline{\text { Reflections }}$}

"Place" has many meanings, most of them relatively localized but some related to regional and national linkages, such as strong identification with athletic teams. But in every case, place is deeply and complexly embedded in relationships with different scales, many of which are not well-understood, in part because data on such interconnections are limited.

People in local places care about their nation in terms of prestige and status, and also as a source of unfunded mandates for local actions. They care about their region as a label that they cannot escape, in the accents which they share when they speak, and as a layer of government that shapes their tax burdens. Their economies 
and job opportunities are closely linked to private firms that operate at multiple scales, as well as to larger-scale local images that affect opportunities for tourism. They see their children connected with the rest of the world through travel and information technologies and options for accessing information that reshape their identification with local places in ways that are different from their parents.

In some ways, perhaps, this tends to shift the emphasis toward relationships between very localized, even household scales and much larger scales, at the expense of intermediate scales. But for many other human and natural systems that we care about operate, these intermediate scales are the domains of their actions to assure sustainability. In this sense, at least, the forces that relate place to sustainability need attention from us all.

\section{Toward an agenda for progress}

There are a number of rich opportunities for the sustainability science community and the place-oriented political-economic research community to combine their efforts and knowledge in ways that should be productive for both. As an example of conceptual meeting grounds, one of the fundamental tenets of sustainability science is that a development path is only sustainable if it has broad-based social consent (e.g., Denton et al., 2014), which connects with discourses on politically contested space. At the same time, the political-economic research tradition recognizes "spaces as a boundary object" (Opdam et al., 2013) for many kinds of conflicts and efforts for conflict resolution, from the spatial extent of neighborhoods to the importance of many kinds of spatial jurisdictions for social and political processes (an instance is the political fragmentation of decision-making in US urban areas: e.g., Solecki and Leichenko, 2006; Rosenzweig et al., 2011). In the juncture of these interests lies potentials for effective interaction, especially when personal contact networks between leaders of the two communities are numerous through such collective enterprises as IPCC.

There are also rich opportunities for the two communities to collaborate in seeking practical solutions to real-time problems for society. An excellent example is the suggestion by Chapin et al. (2012) of an approach for resolving difficult tradeoffs in climate change responses that might suggest migration, including specific attention to such issues as public participation and sense of place. In this sense, progress together can lead to solutions to spatially-framed, politically-contested tradeoffs for places, beyond discourses about those tradeoffs alone.

\section{$\underline{\text { References: }}$}

AAG, 2003. Global Change and Local Places: Estimating, Understanding, and Reducing Greenhouse Gases, R. Kates, T. Wilbanks, and R. Abler, eds., Cambridge: Cambridge University Press, 2003. 
Adger, N., et al., 2003. “Governance for Sustainability: Towards a 'Thick' Analysis of Environmental Decisionmaking,”" Environment and Planning A 35: 1095-1110.

Adger, N., H. Eakin, and A. Winkels, 2009. "Nested and Teleconnected Vulnerabilities to Environmental Change," Frontiers in Ecology and the Environment, 7: 150-157.

Adger, W. N., Barnett, J., Chapin, F. S., \& Ellemor, H., 2011. “This Must Be the Place: Underrepresentation of Identity and Meaning in Climate Change DecisionMaking". Global Environmental Politics, 11(2), 1-25.

Agnew, J., 2001. "Space and Place," in J. Agnew and D. Livingstone, eds. Handbook of Geographical Knowledge, London: Sage.

Agyeman, J., Devine-Wright, P., \& Prange, J., 2009. “Close to the edge, down by the river? Joining up managed retreat and place attachment in a climate changed world". Environment and Planning A, 41, 509-513.

Amin, A., 2004. "Regions unbound: towards a new politics of place". Geografiska Annaler, 86B 33-44.

Antal, A., M. Dierkes, and H. Weller, 1987. "Cross-National Policy Research: Traditions, Advances, and Challenges," in M. Dierkes, H. Weller, and A. Antal, eds., Comparative Policy Research: Learning from Experience. Aldershot: Gower, 1325.

Bonner, J. T., 2007. Why Size Matters, Princeton: Princeton University.

Bulkeley, H., and M. Betsill, 2005. "Rethinking Sustainable Cities: Multilevel Governaance and the 'Urban' Politics of Climate Change," Environmental Politics 14: $42-63$.

Buttrow, D., and M. Wortman, 2012. "US Status on Climate Change Mitigation. Discussion Paper, Resources for the Future," RFF DP 12-48. Washington, DC, October 2012.

Capistrano, D., et al., 2003. "Dealing with Scale," in Conceptual Framework, Millennium Ecosystem Assessment, Kuala Lumpur: Island Press: 107-126.

CARRI, 2010. Research papers (http://www.resilient.org/publications/)

CARRI, 2011. "A Roadmap to Increased Community Resilience". Community Resilience System Initiative (CRSI) Steering Committee Final Report. Oak Ridge, TN: Community and Regional Resilience Institute. 
Cash, D., and S. Moser, 2000. "Linking Global and Local Scales: Designing Dynamic Assessment and Management Processes," Global Environmental Change 10: 109120.

Cash, D., et al., 2003. "Knowledge Systems for Sustainable Development," PNAS, 100: 8086-8091.

Chapin, F. S., Mark, A. F., Mitchell, R. A., \& Dickinson, K. J. M., 2012. Design principles for social-ecological transformation toward sustainability: lessons from New Zealand sense of place. Ecosphere, 3(5), art40.

Cheng, A, and S. Daniels, 2014. "Examining the Interaction Between Geographic Scale and Ways of Knowing in Ecosystem Management," Forest Science 49: 841854.

Clark, W., 1985. “Scales of Climate Impacts, “ Climatic Change 7:5-27.

Corell, R., 2000. "A Decade of Global Change Research: Accomplishments and Future Directions of Earth System Sciences." Prepared Remarks at a Symposium in His Honor: Fairfax, VA, May 15, 2000.

Costanza, R., and T. Maxwell, 1994. "Resolution and Predictability: An Approach to the Scaling Problem." Landscape Ecology 9: 47-57.

Cutter S.L., Barnes, L., Berry, M., Burton, C., Evans, E., Tate, E., and Webb, J., 2008. “A place-based model for understanding community resilience to natural disasters." Global Environmental Change,18(4) 598-606.

Denton, F., et al., 2014. "Climate-resilient Pathways: Adaptation, Mitigation, and Sustainable Development." In Climate Change 2014: Impacts, Adaptation, and Vulnerability. Contributions of Working Group II to the Fifth Assessment Report of the Intergovernmental Panel on Climate Change. Cambridge: Cambridge University Press; 1101-1131.

Devine-Wright, P., 2013. "Think global, act local? The relevance of place attachments and place identities in a climate changed world". Global Environmental Change, 23(1), 61-69.

Environment Canada, 1997. The Canada Country Study: Climate Impacts and Adaptation. Adaptation and Impacts Research Group, Downsview, Ont.

Fresque-Baxter, J. A. and D.Armitage, 2012. Place identity and climate change adaptation: A synthesis and framework for understanding. WIRE - Climate Change, 3(3), 251-266. 
Gibson, C., Ostrom, E., and Ahn, T.-K., 2000. "The Concept of Scale and the Human Dimensions of Global Change: A Survey." Ecological Economics 32: 217-239.

Graedel, T. and E. van der Voet, eds., 2010. Linkages of Sustainability. Strüngman Forum Report, v. 4. Cambridge, MA: MIT Press, 341-354.

Hagerstrand, T., 1975. "Space, Time and Human Conditions," in A. Karlqvist, L. Lundqvist, and F. Snickars, eds., Dynamic Allocation of Urban Space, Farnborough: Saxon House: 3-12.

Hall, P., 1998. Cities in Civilization, New York: Pantheon.

Holling, F., 1995. "Sustainability: The Cross-scale Dimension," in M. Munasinghe and W. Shearer, eds., Defining and Measuring Sustainability: The Biogeophysical Foundations, Washington: World Bank: 65-75.

Kates, R., ed., 2010. Readings in Sustainability Science and Technology. Center for International Development, Harvard University, Working Paper No. 213. Cambridge, MA: Harvard University.

Kates, R., et al., “Sustainability Science”, Science 292, no. 5517: 641-642.

Kates, R. and T. Wilbanks, 2003. "Making the Global Local: Responding to Climate Change Concerns from the Bottom Up," Environment, 45/3 (April 2003): 12-23.

Kates, R., W. Travis, and T. Wilbanks, 2012. "Transformational Adaptation When Incremental Adaptations to Climate Change Are Insufficient," Proceedings of the National Academies of Science (PNAS), April 2012.

Kristjanson, P., et al., 2009. "Linking International Agricultural Research Knowledge with Action for Sustainable Development." PNAS, 106; 5047-5052.

Liu, J., et al., 2013. "Framing Sustainability in a Telecoupled World," Ecology and Society, 18 (2), $26 \mathrm{ff}$.

Liu, et al., 2015. "Systems Integration for Global Sustainability," Science, 347:963ff.

Liverman, D., 2004. "Who Governs, at What Scale, and at What Price? Geography, Environmental Governance, and the Commodification of Nature," Annals of the Association of American Geographers 94: 734-738.

Massey, Pat. ed., 1995. A Place in the World? Oxford: Oxford University Press.

Mendoza, C., \& Morén-Alegret, R., 2013. “Exploring methods and techniques for the analysis of senses of place and migration". Progress in Human Geography, 37(6), 762-785. 
Merton, R., 1973. The Sociology of Science, Chicago: University of Chicago.

Merton,, R. and E. Barber, 2004. The Travels and Adventures of Serendipity: A Study in Sociological Semantics and the Sociology of Science, Princeton: Princeton University

Millennium Ecosystem Assessment, 2005. Ecosystems and Human Well-being, v. 4: Multiscale Assessments. Washington: Island Press.

Moser, S., 2009. Good Morning America! The Explosive US Awakening to the Need for Adaptation. Sacramento, CA: California Energy Commission and Charleston, SC: NOAA Coastal Services Center.

NRC, 1999. Our Common Journey - A Transition to Sustainability. Washington: NAS/NRC.

NAS/NRC, 2005. Thinking Strategically: The Appropriate Use of Metrics for the Climate Change Science Program. Washington, DC: National Academies Press.

NRC, 2006. Linking Knowledge with Action for Sustainable Development. Washington: NAS/NRC.

NAS/NRC, 2010. Adapting to Impacts of Climate Change, with others, Report of the Panel on Adapting to Impacts of Climate Change, NAS/NRC Committee on America's Climate Choices, May 2010.

NAS/NRC, 2010b. Limiting the Magnitude of Future Climate Change. NAS Committee on America's Climate Choices, 2010.

NAS/NRC, 2011. America's Climate Choices, with others, 2011. NAS/Committee on America's Climate Choices, May 2011.

Naughton, L., 2014. “Geographical narratives of social capital: Telling different stories about the socio-economy with context, space, place, power and agency." Progress in Human Geography, 38(1), 3-21.

New York City Panel on Climate Change, 2010. Climate Change Adaptation in New York City: Building a Risk Management Response. Annals of the New York Academy of Science 1196, May 2010.

Opdam, P., J. Nassauer, Z. Wang, C. Albert, G. Bentrup, J.-C. Castella, C. McAlpine, J. Liu, S. Sheppard, and S. Swaffield. 2013. "Science for action the local landscape scale”. Landscape Ecology, 28:1439-1445.

Parkes, D., and N. Thrift, 1980. Times, Spaces, and Places. New York: Wiley 
Rabe, B. G.,2004. Statehouse and Greenhouse: The Emerging Politics of American Climate Change Policy. Washington, DC: Brookings

Reid, W., F., Berkes, T. Wilbanks, and D. Capistrano, co-eds. Bridging Scales and Knowledge Systems: Linking Global Science and Local Knowledge in Assessments, with Washington: Island Press, 2006.

Robb, J., and W. Riebsame, 1997. Atlas of the New West: Portrait of a Changing Region. New York: Norton.

Rosa, E., A. Dickmann, T. Dietz, and C. Jaeger, eds., 2010). Human Footprints on the Global Environment. Cambridge: MIT.

Rosenzweig, C., W. Solecki, S. Hammer, and S. Mehrotra, eds., 2011. Climate Change and Cities. First Assessment Report of the Urban Climate Change Research Network. Cambridge: Cambridge University Press.

Rosswell, T., R. Woodmansee, and P. Risser, 1998. Scales and Global Change. New Yori: Wiley, 1998.

Rudel, T., 2009. “How Do People Transform Landscapes?” American Journal of Sociology, 115: 129-154.

Snover, A., 2007. Preparing for Climate Change: A Guidebook for Local, Regional, and State Governments. Washington, DC: ICLEI.

Solecki, W., and R. Leichenko, 2006. "Urbanization an the Metropolitan Environment," Environment, 48(4): 8-23.

Stedman, R. C., 1999. "Sense of place as an indicator of community sustainability". The Forestry Chronicle, 75(5), 765-770.

Thompson, D, W., 1992. On Growth and Form, New York: Dover Publications (originally published in 1942).

Tomaney, J., 2014. “Region and Place II: Belonging.” Progress in Human Geography.

Turner, B., et al., 1990. “Two Types of Global Environmental Change: Definitional and Spatial Scale Issues in their Human Dimensions," Global Environmental Change 1: 14-22.

Turner, B., et al., 2003. "A Framework for Vulnerability Analysis in Sustainability Science," PNAS 100: 8074-8079. 
Turner, M., R. O’Neill, and R. Gardner, 1989. "Effects of Changing Spatial Scale on the Analysis of Landscape Pattern," Landscape Ecology 4: 153-162.

UCS, 2008. Northeast Climate Impacts Assessment, Union of Concerned Scientists Cambridge, MA.

U.S. National Climate Assessment, 2014. Washington, DC: U.S. Global Change Research Program.

Verstraete, G., \& Cressell, T., eds., 2002. Mobilizing Place, Placing Mobility: the politics of representation in a globalizing world. Amsterdam: Rodopi B.V.

Wilbanks, T., 1972. "Accessibility and Technological Change in Northern India," Annals, Association of American Geographers, LXII (1972), 427-36.

Wilbanks, T., 1975. "Distance, Diversity, and Stability," in C. K. Blong, ed., Systems Thinking and the Quality of Life (Washington: Society for General Systems Research, 1975), pp. 607-14.

Wilbanks, T., 1980. "Accessibility and Social Change in Northern India," in D. Sopher, ed., An Exploration of India: Geographical Perspectives on Society and Culture (Cornell University Press, 1980), pp. 252-70.

Wilbanks, T., 1984. "Scale and the Acceptability of Nuclear Energy," in M. Pasqueletti and D. Pijawka, eds., Nuclear Power: Assessing and Managing Hazardous Technology, Boulder: Westview, 1984: 9-50.

Wilbanks, T., 1985. "Geography and National Policy," Annals, Association of American Geographers, LXXV (1985): 4-10.

Wilbanks, T., 1988. "Impacts of Energy Development and Use, 1888-2088," in Earth '88: Changing Geographic Perspectives, Washington: National Geographic Society, 1988: 96-114.

Wilbanks, T., 1994. "'Sustainable Development' in Geographic Context," Annals, Association of American Geographers, 84 (1994): 541-57.

Wilbanks, T., 2003. "Integrating Climate Change and Sustainable Development in a Place-Based Context," Climate Policy, 3S1 (2003): 147-154.

Wilbanks, T., 2003. "Geography and Technology," in S. Brunn, S. Cutter, and J. Harrington Jr., eds., Geography and Technology, Dordrecht: Kluwer, 2003: 3-16.

Wilbanks, T., 2003. "Geographic Scaling Issues in Integrated Assessments of Climate Change," in J. Rotmans and D. Rothman, eds., Scaling in Integrated Assessment : Swets and Zeitlinger: 5-34. 
Wilbanks, T., 2006. "How Scale Matters: Some Concepts and Findings," in Reid, Berkes, Wilbanks, and Capistrano, op. cit.: 25-40.

Wilbanks, T., 2007. "Scale and Sustainability," Climate Policy, special issue on Integrating Climate Change Actions into Local Development, $7 / 4$ (2007): 278287.

Wilbanks, T., 2009. "How Geographic Scale Matters in Seeking Community Resilience," CARRI Research Paper Number 7, Community and Resilience Institute.

Wilbanks, T., 2011. "Inducing Transformational Energy Technological Change," in W. Nordhaus and N. Nakicenovic, eds., Technological Change and Global Warming, special issue of Energy Economics, 33.4 (July 2011): 699-708.

Wilbanks, T., 2014. "Scale and Sustainability," Association of American Geographers, Tampa, FL, April 2014.

Wilbanks, T., et al., 2009. “Generic Lessons Learned about Societal Responses to Emerging Technologies Perceived as Involving Risks," ORNL/TM-2009/114.

Wilbanks, T. and R. Kates, 1999. "Global Change in Local Places," Climatic Change, 43/3 (1999): 601-628.

Wilbanks, T. and R. Kates, 2010. "Beyond Adapting to Climate Change: Embedding Adaptation in Responses to Multiple Threats and Stresses," Annals of the Association of American Geographers, 100/4 (October 2010): 719-728.

Wilbanks, J., and Wilbanks, T., 2010. "Science, Open Communication, and Sustainable Development," special issue: Advanced Forum for Sustainable Development, Sustainability, 2 (2010): 993-1015.

Wilbanks, T., S. Fernandez, et al., 2014. Climate Change and Infrastructure, Urban Systems, and Vulnerabilities. Washington: Island Press, 2014.

WRI, 2012. "GHG Mitigation in the United States: An Overview of the Current Policy Landscape." Discussion Paper, World Resources Institute, November 2012.

Zucker, L., and M. Derby, 1996. " "Star Scientists and Institutional Transformation: Patterns of Invention and Innovation in the Formation of the Biotechnology Industry," PNAS, 93: 12709-12716.

Acknowledgements 
Valuable contributions from several reviewers are acknowledged; and support from the Integrated Assessment Research Program of the Office of Science, US Department of Energy, is also gratefully acknowledged. 